Original paper

\title{
Prevalence of hepatitis delta infections among HBs-antigen-positive inhabitants of southeastern and northwestern parts of Poland
}

\author{
Robert Pleśniak¹, Marta Wawrzynowicz-Syczewska² \\ 'University of Rzeszów, Clinical Department of Infectious Diseases, Medical Center in Lancut, Poland \\ 2Department of Infectious Diseases, Hepatology and Liver Transplantation, Pomeranian Medical University in Szczecin, Poland
}

\begin{abstract}
Hepatitis delta (HDV) virus still poses a serious health problem worldwide. Being a satellite particle, it may complete its life cycle only in the presence of HBs antigen produced by hepatitis B virus (HBV). According to epidemiological data, about $5 \%$ of $\mathrm{HBs}$ antigen carriers are infected with this virus, which equates to approximately 15-20 million individuals worldwide. Although the infection with both HBV and HDV viruses is considered to be the worst form of viral hepatitis, the only approved treatment, with pegylated interferon $\alpha$, is not satisfactory. Thus effective and safe therapy is still lacking, which stands in contrast to the latest development in therapeutic areas of HBV and hepatitis $\mathrm{C}$ virus (HCV) infections. As the exact data on prevalence of this infection in some countries as well as natural history of this disease are still incomplete, further studies are warranted. Polish investigations on this field are very scarce and at most dating from the 1990s. This publication makes another attempt to broaden our knowledge of this temporarily forgotten but still ongoing and complex problem.
\end{abstract}

Key words: hepatitis delta, hepatitis B virus, cirrhosis, hepatocellular carcinoma.

Address for correspondence

Robert Pleśniak, PhD, University of Rzeszów, Clinical Department of Infectious Diseases, Medical Center in Lancut, 5 Paderewskiego St., 37-100 Łańcut, phone: +48 1722402 92, fax: +48 1722402 44, e-mail: robert.plesniak@wp.pl

\section{Introduction}

Infection caused by the hepatitis delta virus (HDV) still poses an important epidemiological and clinical problem in different areas of the world. According to the World Health Organization (WHO) data this infection concerns approximately $5 \%$ of individuals who are also infected with hepatitis B virus (HBV), which means 15-20 million subjects with chronic HDV disease worldwide [1]. Moreover, this is a population of patients for whom the effective therapeutic offer is still very limited and this situation, in contrast to the developments in chronic B and C hepatitis treatments, did not change in the last three decades.

HDV, the only representative of the Deltavirus genus, is the smallest animal virus $(35-37 \mathrm{~nm}$ in diameter) and is phylogenetically derived from the line of plant viruses (viroids). Having single stranded RNA in its genome and not having even a single enzymatic machinery for replication, HDV requires the presence of HBV for its life cycle by using B surface antigen (HBsAg) to create capsid structures. Thus, HDV is classified as a HBV satellite virus, sharing with $\mathrm{HBV}$ the same routes of infection, mostly via sexual and bloodborne contacts [2-4]. In contrast to HBV, mother-tochild vertical transmissions of HDV are rather rare [5].

\section{Epidemiology}

The prevalence of HDV infections in different geographical regions varies significantly, being higher than 20\% among HBV carriers in the Amazonian region, Central Africa, the Middle East, the Mediterranean Basin, South-East Asia and Mongolia, and between 3\% and 8\% in Europe and in North America. The lowest European rates are observed in Scandinavia and the highest - around 25\% - in Romania [6, 7]. 
HDV is divided into 8 genotypes, but the clinical and epidemiological significance of each genotype is not clearly documented. Genotype 1 is prevalent worldwide, genotypes 2 and 4 are present in the Far East (Japan, Taiwan, eastern Russia), genotype 3 is common in the Amazonian basin, and the remaining four genotypes are found in Africa. Some reports relate genotype 3 of HDV to a higher frequency of fulminant liver failure as well as more aggressive course of chronic infections [8].

\section{Clinical course}

The are two mechanisms of HDV infection. The first one, less frequently observed, is concomitant HBV and HDV infection with the clinical course similar to acute or even hyperacute B hepatitis and the elimination rate of both viruses the same as in HBV monoinfection (around 95\%). The second mechanism is HDV infection superimposing on already existing HBV infection. In this scenario clinical and/or laboratory exacerbation of chronic HBV disease can be observed at the moment of superinfection, and the chronicity rate of HDV infection is as high as $80 \%$. Chronic HBV/ HDV hepatitis can be a mild disease with very slow progression of fibrosis in liver tissue, lasting decades, but there is a lot of evidence that HDV exacerbates inflammatory processes and leads to liver cirrhosis within 5-10 years in 70\% of patients, even in those of young age, and is connected with the increased risk of hepatocellular carcinoma (HCC). Thus, HBV/HDV coinfection is considered the most aggressive form of chronic viral hepatitis $[4,9]$.

Interplay between the two viruses is not uniform. According to a Spanish study on $33 \mathrm{HBV} / \mathrm{HDV}$ co-infections, in $54.5 \%$ of patients HDV replication was dominant, in one third of patients there was a higher replication rate of $\mathrm{HBV}$, and in $15.2 \%$ of infected subjects levels of viremia were similar for both $B$ and D viruses. The authors suggest a higher suppressive influence of HDV on HBV replication than vice versa [10].

\section{Diagnostics}

The first diagnostic step for HDV infection is testing for circulating class $\mathrm{M}$ and class $\mathrm{G}$ anti-HDV antibodies in HBsAg-positive patients. In case of a positive result for anti-HDV an "active" replicative delta hepatitis should be confirmed by the detection of serum HDV RNA. There is no evidence that direct testing for HDV RNA is of any use if anti-HDV antibodies are absent. A positive result for HDV RNA indicates ongoing infection and a negative one confirms contact with the virus in the past and recovery from HDV infection. Some laboratories offer quantification of HDV RNA, but there are no firm data that the level of viremia correlates with the histological severity of the disease $[8,11]$. In HDV RNA-positive patients, further evaluation of grading and staging of liver disease, as well as surveillance for liver cancer, is indicated [7].

\section{Treatment}

Currently, the only treatment for HDV infection, recommended by the experts, is recombinant or pegylated interferon $\alpha($ IFN- $\alpha)$. Several nucleoside or nucleotide analogs used for HBV treatment have been shown to be ineffective against HDV $[12,13]$. 48 -week therapy with rIFN- $\alpha$ or PEG IFN- $\alpha$ allows one to achieve a sustained response, defined as HDV RNA clearance within 6 months after treatment completion, in about $20-25 \%$ of treated patients only $[14,15]$. Thus, this treatment modality is far from ideal. Attempts to combine interferons either with analogs or with ribavirin brought no favorable effect on HDV [16]. Treatment with IFNs is safe in patients with mildly or moderately advanced liver disease, but it is contraindicated in individuals with decompensated cirrhosis and not recommended in compensated cirrhosis as decompensation may occur. In case of high activity of hepatitis, treatment with IFN- $\alpha$ can be repeated, but still the effectiveness is low [17].

No wonder that alternative treatment options for delta hepatitis are being explored in numerous clinical trials. Among these, the most promising are lonafarnib (prenylation inhibitor) [18] and a lipopeptide HBV entry inhibitor, known as Myrcludex B. The latter has been used alone as well as in combination with IFN- $\alpha$, and proved to decrease HBV and HDV viremia levels significantly, especially when used in combination $[19,20]$.

Finally, preliminary data have been presented for oral nucleic acid polymers, but despite effective HDV RNA declines during treatment, there were frequent intestinal side-effects, limiting their use [21].

The most desirable treatment end-point, albeit very rarely achieved, is the elimination of HBsAg with or without seroconversion to anti-HBs. Therefore, realistic and satisfactory antiviral efficacy against HDV is disappearance or stable decline of HDV RNA accompanied by the decline of HBsAg concentration [2, 4, 7-9].

\section{Development of hepatocellular carcinoma}

A lot of attention is paid to the possible role of HDV in the development of hepatocellular carcinoma (HCC). Direct carcinogenesis of HDV by altering 
DNA methylation is being suggested, but despite the higher frequency of HCC among HBV/HDV coinfected patients, it is a matter of debate to what extent HDV infection is associated with a risk of a cancer. The increased frequency of HCC in coinfected patients may be simply explained by the preexisting cirrhosis caused by chronic HBV infection [22, 23].

\section{Prognosis}

In an Italian study of a cohort of 299 anti-HDV-positive patients the probability of 20 -year survival was estimated at $86 \%$ and active viral replication was the only factor increasing the overall mortality [24]. Interestingly, in another study it was found that better survival was related to previous treatment with IFN, even if there was no therapeutic efficacy [25]. Nevertheless, HDV coinfection is commonly considered as a factor worsening prognosis in comparison with $\mathrm{HBV}$ monoinfection $[2,4,7-9]$.

\section{Material and methods}

The study of anti-HDV seroprevalence was conducted in the Infectious Diseases Outpatient Department of the Medical Center of Lancut between May and October 2017. There were 138 Caucasian patients, 58 females and 80 males at the median age of 49.4 years (22-88 years), inhabitants of the South-East region of Poland, included in the study. All of them were HBsAg positive for a period of time longer than 6 months prior to sampling. In each patient $5 \mathrm{ml}$ of blood was taken and ELISA for qualitative determination of total antibodies to hepatitis delta virus was performed (ETI-AB-DELTAK-2 test, DiaSorin). Those patients who turned out to be anti-HDV positive have been carefully analyzed in respect to epidemiological data, efficacy of treatment and grading and staging of liver disease.

\section{Results}

In the cohort of $138 \mathrm{HBsAg}$-positive subjects, who are under surveillance of the Infectious Diseases Outpatient Department of the Medical Center of Lancut, anti-HDV antibodies were detected in 3 patients (2.2\%), one female and two males. This is consistent with some other studies showing HDV seroprevalence in $2-5 \%$ of HBsAg-positive patients $[1,3,4,6]$. In the Department of Infectious Diseases, Hepatology and Liver Transplantation of the Pomeranian Medical University a group of $58 \mathrm{HBsAg-positive} \mathrm{patients} \mathrm{was}$ tested for anti-delta antibodies during the same period of time and none proved to be anti-HDV positive (data not published). We decided to present each of the three
$\mathrm{HBV} / \mathrm{HDV}$ coinfected patients separately as the course of the disease and disease burden differ significantly. It is worth adding that none of these patients was HCV or HIV positive, none traveled to the area endemic for HDV, and none had any contacts with people who lived or traveled to the endemic areas.

\section{Case 1}

It concerns a 38-year-old woman with subclinical hyperthyroidism and $\mathrm{C} 3 / \mathrm{C} 4$ hypocomplementemia, who was diagnosed with chronic HBe-negative hepatitis type $\mathrm{B}$ during routine testing at her first pregnancy. The moment of infection was difficult to establish; most likely it happened at the time of a car accident, prolonged hospitalization, surgery and blood transfusion at the age of 8 years. During pregnancy liver enzymes remained normal and HBV DNA level did not exceed $2000 \mathrm{IU} / \mathrm{ml}$. A few months after the delivery of a healthy baby in 2013 a significant increase (> $100 \mathrm{U} / \mathrm{l}$ ) of alanine aminotransferase (ALT) was noted. Liver biopsy was performed at that time and according to the METAVIR classification histological activity was graded 2 and staging was graded 1 . At the beginning the patient refused treatment with pegylated interferon, but due to a steady increase in viremia level, which exceeded $10000 \mathrm{IU} / \mathrm{ml}$ after two years of observation, and high biochemical activity of the disease, treatment with PEG-IFN a2a was started in 2015. Viremia level at the beginning of treatment was $12400 \mathrm{IU} / \mathrm{ml}$, there was seroconversion to anti-HBe antibodies, ALT activity was $102 \mathrm{U} / \mathrm{l}$ and quantitative measurement of HBsAg was $60450 \mathrm{IU} / \mathrm{ml}$. During 48-week treatment, which was well tolerated, decrease of HBV DNA up to $28 \mathrm{IU} / \mathrm{ml}$, ALT normalization and HBsAg decrease by $0.6 \mathrm{log}$ were achieved. In the follow-up period liver enzymes remained stable and normal, viremia level was low and did not exceed $124 \mathrm{IU} / \mathrm{ml}$ and $\mathrm{qHBs}$ did not increase above $20000 \mathrm{IU} / \mathrm{ml}$. Unfortunately, HDV DNA was not performed and it is not known whether this virus responded to IFN therapy as well. However, this effect is not very frequent in IFN-treated patients.

\section{Case 2}

It concerns 54-year-old male patient, otherwise healthy, who was diagnosed with chronic HBV infection at the age of 20 years during army service. The exact moment of infection is difficult to establish; the serological status of his mother remains unknown, there were two tattoos done before HBsAg testing and a few dental interventions. He denies illicit substances use as well as alcohol abuse. He has smoked 20 cigarettes per 
day since his twenties. Before presenting in the Medical Center of Lancut he did not seek any medical help. At baseline (January 2016) liver enzymes were normal, $\mathrm{HBe}$ antigen was negative and the patient was anti-HBe positive, HBV DNA level was low (24 IU/ml) and qHBs was also low $(89.91 \mathrm{IU} / \mathrm{ml})$. Chronic viral HBe-negative infection type $\mathrm{B}$ was diagnosed (previously described as a "healthy" or nonactive carrier of HBsAg). Elastography, performed in October 2016, showed no significant liver stiffness $(5.1 \mathrm{kPa})$ corresponding to fibrosis grade $0 / 1$ according to the METAVIR scale. During two-year follow-up the patient continued with this status.

\section{Case 3}

It concerns a 45-year old male patient, cigarette smoker (40 cigarettes/day for more than 30 years) and long-lasting alcohol abuse. HBsAg was first detected in his twenties during army service. The exact moment of infection is not possible to indicate; the serological status of his mother remains unknown and the epidemiological history is not remarkable (antibiotic injections and small dental interventions in childhood). Before HBsAg detection the patient was not under medical control. At the Medical Center of Lancut and subsequently during hospitalization in the Infectious Disease Department the patient was diagnosed with compensated cirrhosis (B8 according to the CTP scale) complicated by multifocal lesions in the liver, radiologically consistent with HCC. Guided biopsy was performed and the diagnosis of HCC was confirmed by the pathologist. Due to multiple lesions outside transplant criteria the patient was not listed for liver transplantation. His viral status was the following: $\mathrm{HBeAg}$ negative, anti-HBe positive, HBV DNA $6.77 \times 10^{5} \mathrm{IU} / \mathrm{ml}$, qHBs $3654 \mathrm{IU} / \mathrm{ml}$. $\alpha$-phetoprotein (AFP) at the level of $448 \mathrm{ng} / \mathrm{ml}$ was typical for the diagnosis of HCC. Liver enzymes were elevated (ALT $115 \mathrm{U} / \mathrm{l}$ ). Treatment with the nucleoside analog entecavir (ETV) in a daily dose of $1 \mathrm{mg}$ was started. Because of the futility of any surgical treatment, palliative therapy with sorafenib was started in April 2017. Neither suppression of HBV replication nor normalization of liver enzymes was achieved during a few months of ETV treatment. The lowest level of HBV DNA obtained on ETV was $459 \mathrm{IU} / \mathrm{ml}$. Unfortunately, HCC progressed on treatment with sorafenib and the patient died in December 2017.

\section{Discussion}

The three cases of chronic hepatitis B coinfected with delta virus presented in this report differ with respect to the clinical course and the potential role of HDV in disease progression. It is consistent with the other observations on different influence of HDV on chronic HBV infection from no influence at all (as in case 2) to aggressive acceleration of liver fibrosis and the development of HCC (as in case 3) [26, 27]. However, the small sample of patients included in the study and, moreover, the few anti-HDV-positive subjects that have been discovered during testing do not allow us to draw any conclusions and make general statements. Additionally, in patient 3 a history of alcohol abuse, but not necessarily HDV co-infection, was an important risk factor of the disease progression. In none of these three cases were we able to indicate even the approximate moment of HDV infection (co-infection? superinfection?) and therefore the duration of $\mathrm{HBV} / \mathrm{HDV}$ disease. It was not possible to perform PCR for HDV RNA, and thus to confirm active HDV replication, but this information would not allow the length of the infection to be specified either. According to the available literature, HDV superinfection of already existing chronic HBV infection is more frequent than co-infection with the two viruses. In our cases it was not possible to indicate the moment of $\mathrm{HBV}$ infection, either.

There are scarce data on anti-HDV seroprevalence in Poland. There are only a few Polish publications on the presence of anti-delta antibodies among HBV-infected patients, and according to these scarce data seroprevalence is around 5\% [28, 29], excluding one study in which a high risk group of coinfection was selected [30]. It is not known whether anti-HDV seroprevalence is stable in Poland or has been changing recently taking into consideration some migration movements and more frequent traveling of Poles. The presented cases lead to reflection that it is worth taking care of the problem of somehow forgotten delta virus and introducing standardized anti-HDV testing on a larger scale. Extensive clinical trials among HBsAg-positive Polish patients are warranted.

\section{Disclosure}

Authors report no conflict of interest.

\section{References}

1. http://www.who.int/news-room/fact-sheets/detail/hepatitis-d

2. Lempp FA, Urban S. Hepatitis delta virus: replication strategy and upcoming therapeutic options for a neglected human patogen. Viruses 2017; 9: E172.

3. Taylor JM. Hepatitis delta virus. Virology 2006; 344: 71-76.

4. Rizzetto M. The adventure of delta. Liver Int 2016; 36 (Suppl S1): 135-140. 
5. Sellier PO, Mavlin S, Bercot B, et al. Hepatitis B virus-hepatitis $D$ virus mother-to-child co-transmission: A retrospective study in a developed country. Liver Int 2018; 38: 611-618.

6. Noureddin M, Gish R. Hepatitis delta: epidemiology, diagnosis and management 36 years after discovery. Curr Gastroenterol Rep 2014; 16: 365.

7. Elazar M, Koch C, Glenn JS. Hepatitis delta infection - current and new treatment options. Best Pract Res Clin Gastroenterol 2017; 31: 321-327.

8. Botelho-Souza LF, Vasconcelos MPA, Dos Santos AO, et al. Hepatitis delta: virological and clinical aspects. Virol J 2017; 14: 177.

9. Thomas E, Yoneda M, Schiff ER. Viral hepatitis: past and future of HBV and HDV. Cold Spring Harb Perspect Med 2015; 5: a021345.

10. Schaper M, Rodriguez-Prias F, Jardi R, et al. Quantitative longitudinal evaluation of hepatitis delta virus RNA and hepatitis $B$ virus DNA shows a dynamic, complete replicative profile in chronic hepatitis B and D. J Hepatol 2010; 52: 658-664.

11. Zachou K, Yurdaydin C, Drebber U, et al. Quantitative HBsAg and HDV-RNA levels in chronic delta hepatitis. Liver Int 2010; 30: 430-437.

12. Niro GA, Ciancio A, Tillman HL, et al. Lamivudine therapy in chronic delta hepatitis: a multicentre randomized-controlled pilot study. Aliment Pharmacol Ther 2005; 22: 227-232.

13. Kabacam G, Onder FO, Yakut M, et al. Entecavir treatment of chronic hepatitis D. Clin Inf Dis 2012; 55: 645-650.

14. Heidrich B, Yurdaydin C, Kabacam G, et al. Late HDV-RNA relapse after peginterferon alpha-based therapy of chronic hepatitis delta. Hepatology 2014; 60: 87-97.

15. Heller T, Roman Y, Koch C, et al. Long-term therapy of chronic delta hepatitis with peginterferon alpha. Aliment Pharmacol Ther 2014; 40: 99-104.

16. Gunsar F, Akarca UF, Ersoz G, et al. Two-year interferon therapy with or without ribavirin in chronic delta hepatitis. Antivir Ther 2005; 10: 721-726.

17. Samullah S, Bikharam D, Nasreen T. Treatment of chronic hepatitis delta virus with peg-interferon and factors that predict sustained viral response. World J Gastroenterol 2012; 18: 93-98.

18. Koh C, Canini L, Dahari H, et al. Oral prenyaltion inhibitor with lonafarnib in chronic hepatitis D infection: a proof-ofconcept randomized, double-blind, placebo-controlled phase 2A trial. Lancet Infect 2015; 15: 1167-1174.

19. Rizzetto M, Niro GA. Myrcludex B, a novel therapy for chronic hepatitis D? J Hepatol 2016; 65: 465-466.

20. Bogonolov P, Alexandrov A, Voronova N, et al. treatment of chronic hepatitis D with the entry inhibitor Myrcludex B: first results of a phase Ib/IIa study. J Hepatol 2016; 65: 490-498.

21. Bazinet M, Pantea V, Cebotarescu V, et al. Significant reduction of HBsAg and HDV RNA by the nucleic acid polymer REP 2139 in Caucasian patients with chronic HBV/HDV co-infection. J Hepatol 2015; S257-258

22. Ji J, Sundquist K, Sundquist J. A population-based study of hepatitis $\mathrm{D}$ virus as potential risk factor for hepatocellular carcinoma. J Nat Cancer Inst 2012; 104: 790-792.

23. Fretas N, Salisse J, Cunna C, et al. Hepatitis delta virus infects the cells of hepadnavirus-induced hepatocellular carcinoma in woodchucks. Hepatology 2012; 56: 76-85.

24. Romero R, Del Ninno E, Rumi M, et al. A 28-year study of the course of hepatitis delta infection: a risk factor for cirrhosis and hepatocellular carcinoma. Gastroenterology 2009; 36: 1629-1638.
25. Farci P, Roskams T, Chessa L, et al. Long-term benefit of interferon alpha therapy of chronic hepatitis D: regression of advanced hepatic fibrosis. Gastroenterology 2004; 126: 1740-1749.

26. Fattovich G, Gustina G, Christensen E, et al. Influence of hepatitis delta virus infection on morbidity and mortality in compensated cirrhosis type B. The European concerted action on viral hepatitis. Gut 2000; 46: 420-426.

27. Buti M, Homs M, Rodriguez-Frias F, et al. Clinical outcome of acute and chronic hepatitis delta over time: a long-term follow-up study. J Viral Hepat 2011; 18: 434-442.

28. Bielawski KP, Zietkowski D, Charmuszko U, et al. Hepatitis delta virus infection in chronically HBV-infected patients from northern Poland. Arch Virol 2006; 151: 1207-1215.

29. Chlabicz S, Grzeszczak A, Lapinski TW, et al. Search for hepatitis delta virus (HDV) infection In hepatitis $C$ patients in northeastern Poland. Comparison with anti-HDV prevalence in chronic hepatitis B. Eur J Epidemiol 2003; 18: 559-561.

30. Laskus T, Radkowski M, Lupa E, et al. Prevalence of markers of hepatotropic viruses among drug-addicts In Warsaw, Poland. J Hep 1992; 15: 114-117. 